CLINICAL ETHICS

\title{
Choosing Health and the inner citadel
}

P Allmark

See end of article for

authors' affiliations

J Med Ethics 2006;32:3-6. doi: 10.1136/jme.2005.011999

Correspondence to:

Correspondence to:
Peter Allmark, PhD, Samuel Fox House, Northern General Hospital, Sheffield S5 7AU, UK; p.j.allmark@ shef.ac.uk

Received 21 February 2005 In revised form

21 April 2005

Accepted for publication 22 April 2005
It is argued in this paper that the latest UK government white paper on public health, Choosing Health, is vulnerable to a charge of paternalism. For some years libertarians have levelled this charge at public health policies. The white paper tries to avoid it by constant reference to informed choice and choice related terms. The implication is that the government aims only to inform the public of health issues; how they respond is up to them. It is argued here, however, that underlying the notion of informed choice is a Kantian, "inner citadel" view of autonomy. According to this view, each of us acts autonomously only when we act in accord with reason. On such a view it is possible to justify coercing, cajoling, and conning people on the basis that their current behaviour is not autonomous because it is subject to forces that cause irrational choice, such as addiction. "Informed choice" in this sense is compatible with paternalism. This paternalism can be seen in public health policies such as deceptive advertising and the treatment of "bad habits" as addictions. Libertarians are bound to object to this. In the concluding section, however, it is suggested that public health can, nonetheless, find ethical succour from alternative approaches.
$\mathrm{T}$ his paper argues that the latest UK government white paper on public health, Choosing Health, ${ }^{1}$ is vulnerable to criticism as paternalist despite its emphasis on "informed

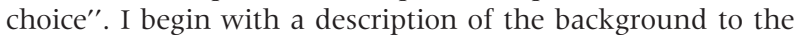
white paper and its focus on choice. Choice is invoked by the white paper in order to absolve itself of charges of paternalism. I suggest that the white paper's view of choice reflects a Kantian account of autonomy. This deems acts to be autonomous only when they are fully rational. This is seen most clearly in the white paper's conflation of informed choice with the right, healthy choice. The idea is that an informed (autonomous) person would only ever make a healthy choice. It also lays the foundation for paternalist interventions aimed at bringing out the autonomous person (the inner citadel) that lies behind the currently nonautonomous person who is making irrational, unhealthy choices. For this reason, an emphasis on informed choice is consistent with paternalist interventions. In the concluding sections I suggest some responses to this point.

\section{BACKGROUND}

Since 1997 the UK has had a centre left (Labour) government that has been active in developing public health policies. It has been mindful of the criticism that, prior to 1997, such policies focused too greatly on individual behaviour and not enough upon broader social factors affecting health. An earlier centre left government produced a white paper entitled Prevention and Health: Everybody's Business, which condemned people's "overindulgence and unwise behaviour". $^{2}$ This emphasis remained under the Conservative Thatcher government. Under the Labour government, by contrast, the white papers started saying such things as,

\section{We believe that the social, economic and environmental factors tending towards poor health are potent. ${ }^{3}$}

The latest white paper, Choosing Health, maintains this change in emphasis. It also tackles a further criticism that has emerged over the last twenty years, particularly from libertarians. They accuse public health policies of generating a "nanny" (paternalist) state that, for our own good, attempts to prevent us behaving in ways we desire. The white paper believes it can avoid this criticism through an emphasis on informed choice. Ethically, this seems reasonable. People are to be given information that will help them make choices; they will also be given support if they want to make changes such as giving up smoking. If there were to be any criticism it might be that the dependence on the idea of informed choice alone ignores the constraints within which people make choices. ${ }^{4}$ The government should follow the logic of its prohibitive action against the tobacco industry and take similar action against-for example, the food industry. The libertarian critics may not, however, be that easily silenced. ${ }^{5}$ To understand their concern it is necessary first to examine the concept of autonomy on which informed choice depends.

\section{AUTONOMY}

The literature on autonomy is extensive; here I shall only draw upon that which is necessary to make the point that the concept of informed choice is more problematic than it first appears.

All animals are, to use Aristotle's terminology, self movers ${ }^{6}$ - that is, they have the capacity to act without being acted upon and with some degree of intention. People are animals and, therefore, self movers; however, we also attribute to them self rule or autonomy. The key difference between self movers and self rulers lies in the control the latter have over their desires. Animals initiate action on the basis of their desires but cannot control their desires. Humans initiate action on the basis of desires over which they can exert some degree of control because they possess reason. As such, their actions are, to some extent and some of the time, based on their purposes; they see some good in what they choose. This is sometimes termed their "view of the good".

Autonomy requires some degree of authenticity and rationality. Someone with a severe mental illness does not possess an authentic view of the good; it is a result of his illness rather than his own emotional and rational development. As such, he is not autonomous. Someone who is completely misinformed cannot act rationally and, therefore, autonomously. It is, however, a matter of controversy as to how much authenticity and rationality is required. Accounts of autonomy can be divided into two broad types: Kantian and Millian. ${ }^{7}$ 
Those in a Kantian tradition stress a high degree of rationality and authenticity. An autonomous act is one that accords with the moral law; any immoral or morally neutral act is not autonomous. ${ }^{8}$ This is because only acts that accord with the moral law are performed fully in accord with reason; they are fully rational. All other acts are contaminated by desire that is, by its nature, less than fully rational. Accounts in a Millian tradition are less demanding. ${ }^{10-13}$ An act is autonomous provided it arises from one's authentic desires and reasons. It matters not whether these reasons are good or sensible, only that they are the agent's own.

Berlin $^{14}$ raises a concern that is relevant here. His discussion concerns liberty rather than autonomy. He draws a distinction between negative and positive liberty. Negative liberty is the freedom to act in accord with one's desires. Positive liberty is freedom to act in a fully authentic way. For this, one must be free from all forces that affect one's desires apart from reason itself. One's true self is one's fully rational self. Berlin attributes such a view to Kant, but also to Plato and the Stoics. Marcus Aurelius ${ }^{15}$ says:

The mind which is free from passions is a citadel, for man has nothing more secure to which he can fly, for refuge and for the future [to] be inexpugnable. He then who has not seen this is an ignorant man; but he who has seen it and does not fly to this refuge is unhappy.

Berlin pejoratively terms this the "inner citadel" view. The danger of such a view is that one may justify removing negative liberty for the sake of positive liberty; if people are making inauthentic choices whilst negatively free it is better to coerce, cajole, or con them into making authentic ones: in this way they become positively free. At the time Berlin was writing he had in mind such things as the oppression of people living under Communist regimes.

\section{AUTONOMY AND “INFORMED CHOICE"}

There are a number of reasons to suspect that the white paper's conception of "informed choice" reflects a "positive liberty" or Kantian view of autonomy. In the first place, it is noteworthy that the document uses the terms "informed choice" and "healthy choice" almost interchangeably. The implication seems to be that once informed one will necessarily make the healthy choice. Someone who continues to make unhealthy choices is, it follows, not yet informed. In this context, it is noteworthy that Choosing Health sets a number of targets. These targets are nearly all behavioural; they concern reducing the incidence of smoking, obesity, and alcohol intake and increasing exercise and sexual health. In order to meet these targets it is not enough that people are informed, they must also change. A document that is committed to behavioural change through "informed choice" must be based on a view of autonomy that is closer to Kant than Mill. If it were based on a Millian view, the targets would be, say, that $98 \%$ of the population knows the chief dangers of smoking not that they would necessarily give up.

One finds support for this conclusion in an examination of the techniques of public health information. Campbell ${ }^{16}$ draws a helpful distinction between education and indoctrination. This depends primarily on the intention of the educator. If his intention is to appeal to the agent's reason then the activity is education; if it is to induce change in a way that bypasses the agent's reason then it is indoctrination. Often, health education looks like indoctrination. At least two considerations suggest this.

The first is that information is framed to present the strongest case in favour of a healthy choice. In particular, there is a reliance on relative rather than absolute odds. ${ }^{17} \mathrm{We}$ will be told that certain behaviour increases the risk of a disease by many times-for example, that binge drinking increases the risk of liver cirrhosis by sixfold-but not what the original risk was. This looks impressive but is virtually useless for rational decision making: without knowing the absolute risk, how is one to judge the import of a sixfold increase? The second related consideration is that health education materials use the techniques of advertising. An advertisement that shows fat dripping from cigarettes, or squeezed from the aorta of a dead smoker, aims to disgust us. A girl talking to camera about her dead father and his smoking, a tear in her eye, aims to upset us and fill us with guilt: "What a bad father I am to be smoking: please help me change".

On an "inner citadel" view such methods may be justifiable. People who make unhealthy choices are constrained by forces that prevent them acting in accord with their true, inner citadel, self. The "inner citadel" view is that all of us would make the healthy choice were we properly informed and freed from constraints to our reason. Being properly informed will involve us being apprised of the relevant facts; but Choosing Health also talks of a number of ways in which we can be freed from constraints. In the first place, healthy choices need to be available: poverty and the environment can prevent this at present. There needs to be control on advertising by the enemies of healthy choice (such as tobacco firms and "junk food" purveyors). People need help to overcome their addictions. Poverty is cited throughout as a problem for informed and (therefore) healthy choice. In the context of-for example, fighting the deceptive advertising of tobacco firms-one is justified in using deceptive advertising oneself.

\section{OBJECTIONS TO THE INNER CITADEL}

Libertarians in particular may have a number of objections to this. The first is that health is not all there is to a good life. The single mother, living in poverty, who finds that smoking gives her a small pleasure, a bit of "me time", is not making a mistake; she is making a reasoned choice that is right for her. ${ }^{18}$ The same could be said of someone who risks his health through climbing mountains. Public health measures promote a low risk lifestyle that few would enjoy.

This objection is buttressed by criticism of the "population strategy" for public health. ${ }^{19} 20$ Whole populations are targeted to change their behaviour rather than those at high risk. People who drink fairly moderately-for example, say 30 units per week-are nonetheless recommended to reduce their intake. The rationale is that this strategy reduces the whole population alcohol intake and results in greater reduction in ill health than simply targeting those at high risk alone. The key problem is that people at fairly moderate risk through their lifestyle are nonetheless targeted and encouraged to give up things they enjoy for the sake of reducing their risk to one that is as low as possible.

Furthermore, public health measures are hardly consistent in this regard. Some relatively high risk activities, such as horse riding, are not targeted at all. Instead, the focus is on smoking, drinking, eating, and so forth. Public health proponents might well respond that these are the activities that do damage to the greatest number of people. One cannot help feeling, however, that they are also activities selected for opprobrium because they are related to such vices as gluttony, intemperance, and sloth. It is a moot point-for example, whether there is greater danger in drinking 30 units a week than in daily horse riding.

A second objection to the "inner citadel" view arises from the fact that health is a problematic concept. There are numerous accounts of the concept of health. It is helpful to divide them into two main categories: objective and 
subjective. Objective (or naturalist) accounts ${ }^{21}$ describe health and illness as physiological facts about a person. Subjectivist accounts ${ }^{22}$ stress the element of subjective value judgment in attributions of health and illness. It is likely that most healthcare professionals hold some type of objective view. As such, promoting public health is viewed as promoting something that is factual and can be measured. Objective views are, however, hugely problematic. ${ }^{23-25} \mathrm{~A}$ person is not ill simply because her physiology is abnormal. Some abnormality is welcomed (such as high intelligence) and some normality is not (such as male baldness). For something to constitute illness it must be associated with things we disvalue, such as pain and death. As such, it depends on our values; and these values may not necessarily be shared. Deafness is a good example of this. Some deaf people claim that they do not have a health problem (a disability) but simply a different way of life. They would not welcome interventions aimed at eradicating the problem. ${ }^{26}$ The conclusion from these two objections is that there is no reason to expect that people will, once informed, necessarily make healthy choices; people have different values that will lead them to make different choices even when similarly informed.

There are also objections to the idea that there is an "inner citadel" self that will emerge once freed from constraints such as addiction and poverty. At the heart of these objections is the thought that it is wrong to coerce, cajole, and con someone into making "informed choices" on the basis that these are what the person would choose if only they could see reason. One way this is done is through the concept of addiction. Fitzpatrick ${ }^{27}$ criticises the relabelling of "bad habits" as "addictions". He claims that it is in this way that smoking, alcohol, drug abuse, gambling, shopping, and sex (among others) can become behaviours that are viewed as not amenable to reason and, instead, require treatment. The "inner citadel" view is that few, if any, would rationally choose the pleasures of smoking, excess alcohol, and so forth. The libertarian view is, presumably, that many can and do.

Poverty is another concept invoked by the proponents of the "inner citadel" view. The health gap between rich and poor has remained roughly the same since at least Victorian times in the UK. Poor people die earlier and suffer disproportionately from illness. The conclusion is that poverty causes much illness; public health policy must perforce attack poverty. Choosing Health appears to accept this point. The UK already has numerous "health action zones" (areas of poverty, in the main); Choosing Health recommends that future action at first be targeted in these types of areas. Again, the language it uses is redolent of an "inner citadel" view. The poor need more information, more help with addiction, and so forth.

There are, however, grounds to question this account of the relationship between poverty and illness. Health for all groups in the UK has improved enormously since Victorian times. One could say that the health of the poor has kept up with that of the rich even though it has not caught up with it. Furthermore, both the poor and the rich are far better off financially than in Victorian times; the poor are only poor in relative terms. Thus the public health argument here is not that poverty causes illness but that relative poverty causes illness. This is far from obvious. For example, it is clear that if my poverty entails an inability to eat sufficiently, that will cause illness. It is not clear, however, that if my poverty involves me being able to meet all my basic needs but not having as many material goods as others around me, that will cause illness. As Le Fanu ${ }^{28}$ puts it:

Absolute poverty in the form of an inadequate diet, overcrowding, poor hygiene and lack of protection from the elements can harm the human organism and cause disease. Relative poverty cannot.

From a libertarian viewpoint, Choosing Health and similar initiatives are attempting to change the culture of the poor, to make them behave as the middle class do. Furthermore their justification for doing this is that this is how the poor would behave if only they were better informed, could see reason, and could rid themselves of their various addictions. The language of "informed choice" disguises paternalist policy.

\section{Closing remarks}

Choosing Health says the following (Department of Health, ${ }^{1}$ para 6):

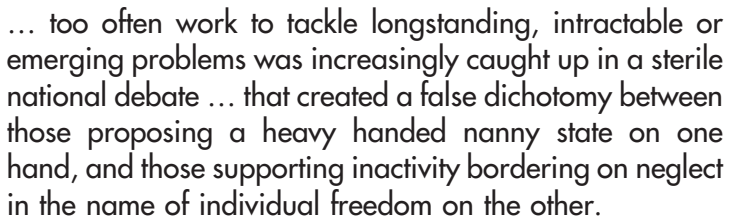

By invoking the concept of informed choice it attempts to bypass this "sterile debate". I have argued that this manoeuvre is unsuccessful. The informed choice of which the white paper speaks reflects an inner citadel view of autonomy that can be and is used to justify paternalist interventions. We should, perhaps, not be surprised that the white paper is unable easily to free itself from the paternalist accusation. Public health promotion involves promoting certain values. These include the values that underlie our conception of health and illness, and the value that we put on health itself. For libertarians this is bound to be objectionable. All that matters from their viewpoint is that people are free to live in accord with their own values; it is not the business of others, and certainly not of the government, to attempt to change those values.

However, one does not have to accept this libertarian conclusion. There are numerous other approaches to public health ethics. ${ }^{29}$ An Aristotelian and communitarian approach-for example-would accept that our ideas of health and its value are based upon value judgments of the good. ${ }^{30}$ They would state, however, that such value judgments could be criticised; some are better than others. It follows that the government may well be justified in promoting some (and discouraging other) visions of the good. Alternatively, the four principles approach might say that public health measures are problematic in terms of respecting people's autonomy but are justified by reference to the other principles, particularly beneficence and justice.

Libertarians have forceful objections to public health policy. Even non-libertarians who believe public health measures to be justified may object to some policies that arise on the basis of the "inner citadel" view. Deceptive advertising, the setting of population behaviour targets, the targeting of medium risk groups, and the assumption that informed choice will necessarily be healthy choice are among the issues that give rise to concern. The key point is that discussion of the ethics of public health is far from sterile.

\section{ACKNOWLEDGEMENT}

I am very grateful to the two anonymous reviewers of this journal for their extensive and helpful comments on an earlier version of this paper.

\section{REFERENCES}

1 Department of Health for England. Choosing health: making health choices easier. London: Department of Health, 2004. 
2 Department of Health and Social Security. Prevention and health, everybody's business: a reassessment of public and personal health. London: DHSS, 1976:39.

3 Department of Health. Saving lives: our healthier nation. London: Department of Health, 1999, ix.

4 McKee M, Raine R. Choosing health? First choose your philosophy. Lancet 2005;365:369-70.

5 O'Neill B. "Informed choice" is no choice at all. Spiked Online 19 Nov 2004 http://www.spiked-online.com/Articles/0000000CA7C4.htm laccessed 11 May 2005)

6 Furley D. Self movers. In: Rorty A, ed. Essays on Aristotle's ethics. Berkeley: University of California Press, 1980:55-68.

7 Holm S. Autonomy. In: Callahan D, Singer P, Chadwick R, eds. Encyclopaedia of Applied Ethics, [vol 1]. London: Academic Press, 1998:267-74.

8 Kant I. Groundwork of the metaphysics of morals [ed Gregor M]. Cambridge: Cambridge University Press, 1998.

9 Korsgaard C. The sources of normativity. Cambridge: Cambridge University Press, 1986.

10 Gray J. Mill on liberty: a defence. London, RKP, 1983.

11 Lindley R. Autonomy. London: Macmillan, 1986.

12 Feinberg J. The moral limits of the criminal law: volume 3: harm to self. New York: Oxford University Press, 1986.

13 Hayry H. The limits of medical paternalism. London: Routledge, 1991.

14 Berlin I. Two concepts of liberty. Four essays on liberty. Oxford: Oxford University Press, 1969:118-72.

15 Marcus Aurelius. Meditations. [trans Long G]: VIII, 48, 3, http:// classics.mit.edu/Antoninus/meditations.html (accessed 11 May 2005).
16 Campbell A. Education or indoctrination? The issue of autonomy in health education. In, Doxiadis S, ed. Ethics in health education Chichester, Wiley, 1991:15-27.

17 Brignell J. The epidemiologists: have they got scares for you! Mere Warminster: Brignell Associates, 2004.

18 Cribb A, Duncan P. Health promotion and professional ethics. Oxford: Blackwell, 2002.

19 Rose G. Sick individuals and sick populations. Int J Epidemiol 2001:30:427-32.

20 Adams J, White $M$. When the population approach to prevention puts the health of individuals at risk. Int J Epidemiol 2004;33:1-4.

21 Boorse C. Concepts of health. In: Van de Veer D, Regan T, eds. Health care ethics: an introduction. Philadelphia: Temple University Press, 359-93.

22 Nordenfelt L. In: On the nature of health [2nd ed]. Dordrecht: Kluwer, 1995.

23 Kennedy I. The unmasking of medicine. London: Granada, 1983.

24 Illich I. Limits to medicine: medical nemesis: the expropriation of health. Harmondsworth: Penguin, 1990.

25 Papineau D. Mental disorder, illness, and biological dysfunction. In: PhillipsGriffiths A, ed. Philosophy, psychology and psychiatry. Cambridge: Cambridge University Press, 1994:73-82.

26 Savulescu J. Deaf lesbians, "designer disability", and the future of medicine. J Med Ethics 2002;325:771-3.

27 Fitzpatrick $M$. The tyranny of health: doctors and the regulation of lifestyle. London: Routledge, 2001.

28 Le Fanu J. The rise and fall of modern medicine. London: Abacus, 2000:371.

29 Roberts M, Reich M. Ethical analysis in public health. Lancet 2002;359:1055-9.

30 Allmark P. Health, happiness and health promotion. J Appl Philos 2005;22:1-15.

\section{1 th European Forum on Quality Improvement in Health Care}

26-28 April 2006, Prague, Czech Republic

For further information please go to: www.quality.bmipg.com

Book early to benefit from a discounted delegate rate 